\title{
Possible bridge between the mind and matter: The physical world is nothing but a projection of the mind consisting of TCP and TRP that, in turn, are the ultimate constituents of any matter also
}

\author{
Dhananjay Pal \\ Email address: \\ dhananjay.pal123@gmail.com,paldhananjay46@yahoo.com
}

Pharmacy College, Bengal School of Technology, Sugandha-Delhi Road, Chuchura, Dist.-Hooghly, West Bengal, INDIA, PIN-712 102

\section{To cite this article:}

Dhananjay Pal. Possible Bridge between the Mind and Matter: The Physical World is nothing but a Projection of the Mind Consisting of TCP and TRP that, in Turn, are the Ultimate Constituents of any Matter also. American Journal of Physical Chemistry.

Vol. 2, No. 5, 2013, pp. 105-116. doi: 10.11648/j.ajpc.20130205.14

\begin{abstract}
A single field emerged at the origin of the universe, already containing within itself the blueprint of the physical universe. The primordial single field triggered the onset of the universe. Most physicists believe that a single super-force dominated the first instants of creation. Scientists have arrived at a simple but decisive conclusion that consciousness is very much a part of the universe, like other objects. Our consciousness model involving thought-carrying particle (TCP), thought retaining particle (TRP) and thought force (TF) signifies the existence of universal consciousness that exists along with the universe. This universal consciousness is a functional state of the universal mind (UM). This UM is evolved at the Big Bang from void. The UM is constituted by these TCP and TRP in the inherent presence of thought force (TF). Thought force (TF) is an expression of universal consciousness. The Thought force (TF) being the primordial quantum field functions as the original super-force. TF being the original super-force functions as the origin of all the fundamental fields. TCP is the carrier of thought force (TF) that, in turn, appears to be the origin of all the fields. The quantized energy $\left(\varepsilon_{T}\right)$ of TCP is responsible to cause the universal consciousness as well as the cosmic microwave background radiation temperature. The individual consciousness owes its origin to the universal consciousness created by the same $\varepsilon_{T}$. The same $\varepsilon_{T}$ is the energy responsible for generating thought force (TF). TF being an expression of the universal consciousness is applicable to any inanimate object as well as to any biological system (having thinking ability). The TF exerts its functions both in vitro and in vivo. Any matter as well as any individual mind is constituted by these TCP and TRP in the inherent presence of thought force (TF) in vitro and thought force (TF) in vivo and these TCP and TRP are originated from the same Void. These TCP, TRP and the thought force (TF) in vitro and thought force (TF) in vivo play significant roles in understanding matter, mind and consciousness and in the formation of a possible bridge between the mind and matter.
\end{abstract}

Keywords: Void, Cosmic Microwave Background Radiation (CMBR), Universal Mind (UM), Thought Force (TF), Though-Carrying Particle (TCP), Thought Retaining Particle (TRP), Quantized Energy $\left(\mathcal{E}_{T}\right)$ of TCP

\section{Introduction}

In Eastern philosophical traditions, consciousness is intrinsic to the universe, whereas in most Western views, consciousness is extrinsic, emerging from complex computation. How can these views be reconciled?

It is most relevant and important to indicate the names of various eminent physicists like Erwin Schrödinger, Eugene Wigner, Brian Josephson, John Wheeler, Roger Penrose,
Henry P Stapp, Freeman J. Dyson, Paul Davies, David Bohm, Basil Hiley, Fritjof Capra, Fred Alan Wolf and Amit Goswami who have addressed the inclusion of consciousness in their work. Consciousness is to be taken into account.

1.1. In contrast to the usual linear sequence of matter, body, life, brain, mind, consciousness, here the proposed cyclic sequence is first universal consciousness (a functional state of the universal mind), and then matter, 
body, life, brain, and regeneration of mind and consciousness. The evolution of life with mind and consciousness is possible purely due to the inherent existence of universal consciousness which exists along with the universe. The human nervous system is evolved to provide an appropriate material structure to individualize the universal consciousness, a characteristic of reality, pervading all manifestations.

Consciousness model of Pal et al [1-3] involving TCP, TRP and thought force $\left(\mathrm{T}_{\mathrm{F}}\right)$ signifies the existence of universal consciousness that exists along with the universe. Pal et al [3] showed that this universal consciousness is a functional state of Universal Mind (UM). Pal et al [3] explained that the UM is evolved at the Big Bang from the eternal Void. This Void, in turn, is the source of infinite energy. And this $\mathrm{UM}$ is a finer matter. The individual mind being a constituent of the UM is also a finer matter. The constituents of the UM and individual mind are the same. The ultimate constituents of matter and mind are the same as both mind and matter are aspects of one fundamental reality, which is called UM. The brain is the mediating link or interface between the individual mind and body.

Pal et al [3] explained that the constituents of the UM are the ultimate constituents of matter itself as everything in this universe is a manifestation of this UM. Pal et al [3] expressed that the UM is constituted by these TCP and TRP in the inherent presence of thought force $\left(\mathrm{T}_{\mathrm{F}}\right)$. Pal et al $[1,3]$ further explained that the ultimate constituents of matter and mind are these TCP and TRP in the inherent presence of thought force $\left(\mathrm{T}_{\mathrm{F}}\right)$ in vitro and thought force $\left(\mathrm{T}_{\mathrm{F}}\right)$ in vivo.

Physicists determined that underlying quantum fields give birth to elementary particles. Bhaumik [4] mentioned that Frank Wilczek pointed out, "In quantum field theory, the primary elements of reality are not individual particles, but underlying fields. Thus, for example, all electrons are but excitations of an underlying field, naturally called electric field". The same holds true for all the fundamental particles of which matter is made.

The existence of matter depends on the existence of force and vice versa. TCP cannot exist without TRP and vice versa. Many physicists believe that unifying all the forces, including gravity, into a single theory would require a phenomenon called super-symmetry. With supersymmetry, every fermion would have a boson twin, and vice-versa. The thought force $\left(\mathrm{T}_{\mathrm{F}}\right)$ is carried by the TCP in the presence of its super-symmetrical partner TRP. TCP that behaves like boson should accompany its supersymmetrical partner TRP that functions like fermion in the generalized simpler way. It is to be noted that these TCP and TRP function like wavicle: wave-particle duality.

\section{Thought Force}

Pal et al [1,3] and Pal [5] explained the existence of thought force $\left(\mathrm{T}_{\mathrm{F}}\right)$. Thought force $\left(\mathrm{T}_{\mathrm{F}}\right)$, an expression of the universal consciousness, is the primordial quantum field that, in turn, functions as the primary unified field. This $T_{F}$ being an expression of the universal consciousness is applicable to any inanimate object as well as to any biological system (having thinking ability). Thus the $\mathrm{T}_{\mathrm{F}}$ being an expression of the universal consciousness exerts its functions both in vitro and in vivo.

Physicists determined that underlying quantum fields give birth to elementary particles. Pal [5] expressed that the thought force $\left(\mathrm{T}_{\mathrm{F}}\right)$ is the primordial quantum field. Thought force $\left(\mathrm{T}_{\mathrm{F}}\right)$ being the primordial quantum field functions as the primary unified field. Thought force $\left(T_{F}\right)$ being the primordial quantum field gives birth to TRP that appears to be the origin of all the matter particles. TCP is the carrier of thought force $\left(\mathrm{T}_{\mathrm{F}}\right)$ that, in turn, appears to be the origin of all the fields. TCP thus appears to be the origin of all the field particles.

In a purpose to involve both the non-living and living systems of the world, Pal [5] has shown the existences of these TCP, TRP and thought force $\left(\mathrm{T}_{\mathrm{F}}\right)$ in vitro and thought force $\left(\mathrm{T}_{\mathrm{F}}\right)$ in vivo. Anyone can call this TCP by any other name, but as the highly developed living system will have to be evolved in the universe in the long run and as the thought of highly developed living system appears to be a kind of force to be called the thought force $\left(\mathrm{T}_{\mathrm{F}}\right)$ in vivo, we considered it is wise to call it as TCP. Further, as the universe exists along with the universal consciousness that, in turn, is created by the quantized energy $\left(\varepsilon_{T}\right)$ of TCP, we had to use the term TCP.

Pal (5) expressed that the non-living system of the world is governed by the thought force $\left(\mathrm{T}_{\mathrm{F}}\right)$ in vitro and this Thought force $\left(\mathrm{T}_{\mathrm{F}}\right)$ in vitro gives rise to $\mathrm{T}_{\mathrm{F}}$ (micro), $\mathrm{SNF}$, EMF, WNF, GF and $\mathrm{T}_{\mathrm{F}}$ (macro) where $\mathrm{T}_{\mathrm{F}}$ (micro) = Thought force in microcosm, SNF = Strong nuclear force, $\mathrm{EMF}=$ Electromagnetic force, $\mathrm{WNF}=$ Weak nuclear force, $\mathrm{GF}=$ Gravitational force and $\mathrm{T}_{\mathrm{F}}$ (macro) $=$ Thought force in macrocosm. It is to be noted here that $\mathrm{T}_{\mathrm{F}}$ (micro) is a stronger force than the SNF and $\mathrm{T}_{\mathrm{F}}$ (macro) is a weaker force even than the GF.

Pal (5) also expressed that the living system of the world is governed by the thought force $\left(\mathrm{T}_{\mathrm{F}}\right)$ in vivo and this Thought force $\left(\mathrm{T}_{\mathrm{F}}\right)$ in vivo is a type of force that represents the biological 'thought' which is the action of mind. This 'thought' being a type of force controls the 'thought processes' involving the firing of neurons through the quantum mechanical activities of these TCP and TRP in the presence of consciousness. Consciousness in living organisms is a process which involves the quantum mechanical activities of these TCP and TRP, the ultimate constituents of any matter as well as any mind in the inherent presence of thought force $\left(\mathrm{T}_{\mathrm{F}}\right)$ in vitro and the thought force $\left(\mathrm{T}_{\mathrm{F}}\right)$ in vivo as indicated by Pal et al [3]. This consciousness, in turn, is the quantized energy $\left(\varepsilon_{T}\right)$ of TCP. The thought force $\left(\mathrm{T}_{\mathrm{F}}\right)$ in vivo is demonstrated in numerous experiments in which thought has an effect on a physical process (often known as mind over matter). This biological 'thought' is a type of force that can cause movement. Controlling movement through thought alone is observed in several experiments conducted by many 
scientists as indicated by $\mathrm{Pal}$ (5). These experiments thus signify the existence of thought force $\left(\mathrm{T}_{\mathrm{F}}\right)$ in vivo.

Pal [5] explained the existence of $\mathrm{T}_{\mathrm{F}}$ (micro) (= Thought force in microcosm). This $\mathrm{T}_{\mathrm{F}}$ (micro) is the strongest interaction (a new class of 'extra strong' interaction). It is stronger than SNF (Strong Nuclear Force).

Pal [5] has also shown the existence of $\mathrm{T}_{\mathrm{F}}$ (macro) (=Thought force in macrocosm). It is the "weakest force"

$$
\varepsilon_{T}=4.384 \times 10^{-16} \mathrm{erg} \equiv 2.73 \times 10^{-4} \mathrm{eV} \equiv 2.73 \mathrm{~K} \cong C M B R \text { temperature } \equiv 2.725 \mathrm{~K} .
$$

This conversion of erg $\equiv \mathrm{eV} \equiv \mathrm{K}$ is given by Weisskopf [6] as follows:

$$
1 e r g \cong 0.6241807 \times 10^{12} \mathrm{eV} \text { and } 10^{-4} \mathrm{eV} \cong 1 K
$$

2.2. Pal et al [3] expressed that the CMBR temperature is due to $\varepsilon_{T}$, the quantized energy of TCP where

$$
\varepsilon_{T}=4.384 \times 10^{-16} \mathrm{erg} \equiv 2.73 \times 10^{-4} \mathrm{eV} \equiv 2.73 \mathrm{~K} \cong C M B R \text { temperature } \equiv 2.725 \mathrm{~K} .
$$

As per Pal et al [3], it is interesting to note that all of the three different equations ultimately give rise to the same result that is equivalent to the CMBR temperature. A sort of relationship is thus observed between the $\varepsilon_{T}$ and the CMBR temperature. This coincidence is thus signifying a probable role of TCP on the maintenance of CMBR temperature. Further, this coincidence is also signifying the existence of these TCP in the presence of TRP. TCP cannot exist without TRP and vice versa. The presence of TCP, TRP and Thought force $\left(\mathrm{T}_{\mathrm{F}}\right)$ in the universe is thus indicated and expressed mathematically. At present we are unable to explain when and how these TCP and TRP decoupled from the primordial cosmic soup.

Pal et al $[1,3]$ showed that the quantized energy $\left(\varepsilon_{T}\right)$ of TCP is responsible to cause the universal consciousness as well as the cosmic microwave background radiation temperature. The individual consciousness owes its origin to the universal consciousness created by the same $\varepsilon_{T}$. Ultimately this $\varepsilon_{T}$ represents universal consciousness. The existence of CMBR temperature indicates the existence of the TCP in the presence of TRP. The existence of TCP ensures the existence of the thought force $\left(\mathrm{T}_{\mathrm{F}}\right)$. Further, this $\mathrm{T}_{\mathrm{F}}$ being an expression of the quantized energy ( $\varepsilon_{T}$ ) of TCP exerts its functions both in vitro and in vivo.

\section{What Is Life}

Life is a state of flux that is being maintained by a typical form of energy which is nothing but the consciousness itself. Pal et al [3] and Pal [7] showed that the quantized energy $\left(\varepsilon_{T}\right)$ of TCP is responsible to cause the universal consciousness as well as the cosmic microwave background radiation temperature. The individual consciousness owes its origin to the universal consciousness created by the same $\varepsilon_{T}$. Pal et al $[1,3]$ and Pal [7] explained that life may be defined as a state of functional manifestation of consciousness that, in turn, is the quantized energy ( $\varepsilon_{T}$ ) of TCP. This $\varepsilon_{T}$ represents universal consciousness.

Thus,

$$
\text { Life }=\mathrm{f}(\text { Consciousness })=\mathrm{f}\left(\boldsymbol{\varepsilon}_{T}\right)
$$

where

$$
\begin{gathered}
\mathcal{E}_{T}=\text { quantized energy of the TCP }=4.384 \times 10^{-16} \mathrm{erg} . \\
\varepsilon_{T}=h v_{T}=h c / \lambda_{T}=4.384 \times 10^{-16} \mathrm{erg}
\end{gathered}
$$

where

$$
\begin{aligned}
& \varepsilon_{T}=\text { quantized energy of the TCP }=4.384 \times 10^{-16} \mathrm{erg}, \\
& \begin{aligned}
v_{T}=\text { frequency of the TCP } \\
\quad=\varepsilon_{T} / \mathrm{h}=66.12 \times 10^{9} \mathrm{~Hz} \cdot=66.12 \mathrm{GHz},
\end{aligned} \\
& \mathrm{h}=\text { Planck's quantum constant }=6.63 \times 10^{-27} \mathrm{erg} \cdot \mathrm{sec}, \\
& \mathrm{c}=\text { free-space velocity of light }=3 \times 10^{10} \mathrm{~cm} / \mathrm{sec}, \\
& \lambda_{T}=\text { wave-length of the TCP }=0.4537 \mathrm{~cm} .
\end{aligned}
$$

\subsection{What Is Consciousness}

Psychologists, neuroscientists, philosophers, and other professionals continue to engage in an ongoing debate as to what consciousness means. In reality, we may never know. Is it a product of the biological and classical physical interactions of the human brain; or is it something more fundamental, perhaps electromagnetic, or the result of quantum physics principles that we don't yet fully understand? Could it be something even more profound than that -- something beyond the scope of science and physics, any kind of physics, for us to understand?

According to the ancient Vedanta, consciousness is not 
an emergent property of matter that comes into existence only through the functioning of the human nervous system. Instead, consciousness is a characteristic of reality, pervading all manifestations. This unbounded field of nature's universal consciousness is not limited to an individual consciousness. From this viewpoint, the role of the human nervous system is to provide an appropriate material structure to individualize the universal consciousness. It appears that inanimate matter itself cannot generate consciousness without the inherent existence of universal consciousness.

Pal et al [2] explained, "Consciousness is the realization of existence, and there are as many states of consciousness as there are states of existence. Every living being has a consciousness of its own depending on complexity of the brain and the activity of the viable numbers of TCP in the presence of TRP; and the state of its consciousness changes every moment of time. Consciousness is the perception of the relation it bears to things and as this relation changes, consciousness changes its character. Consciousness itself does not change; it only moves up and down on the 'scale of the realization' of existence through the 'sub-conscious', 'conscious' and 'super-conscious' states". There is another term called unconscious state. The most usual unconscious state is sleep. A deeper form of unconsciousness is called a coma.

\subsection{Possible Relation of Consciousness with Mind: Possible Relation of Animate with Inanimate through Consciousness}

Modern scientists have not even been able to arrive at a consensus on what should be a definition of the totality of consciousness. The brain is intricately linked to the process of consciousness and consciousness is thought to be a phenomenon of the mind.

It appears that

$$
\text { Consciousness }=\mathrm{f}(\text { mind })
$$

Consciousness is the functional state of mind. Presence of consciousness signifies the presence of mind and vice versa.

It is apparent that

$$
\text { Animate } \neq \text { Inanimate }
$$

Three critical factors which distinguish life from nonliving are consciousness, metabolism and reproduction.

In a gross presentation, we can express from the equation (4):

$$
\text { Animate }- \text { Consciousness }=\text { Inanimate }
$$

Scientists would have to define and characterize consciousness properly. We should have the proper knowledge about the exact characteristics of consciousness in order to address many present day scientific enigmas.

\subsection{Consciousness may be Defined as the 'Self-Organized' Capability of any Living being to Activate TCP and TRP}

Pal et al [3] expressed that consciousness may be defined as the 'self-organized' capability of any living being to activate TCP and TRP, the ultimate constituents of mind and matter and to exert its functions. What can generate, maintain and activate TCP and TRP is called animate having 'active consciousness' and what cannot is called inanimate, i.e., devoid of active consciousness. As anything inanimate does neither have the power to activate the TCP and TRP nor have the capability to catalyze the activity of TCP and TRP, so it cannot generate consciousness. On the contrary, anything animate has the 'self-organized' power to generate, activate and catalyze the activity of TCP and TRP in order to generate and maintain consciousness along with the vital living force. Prigogine et al [8] explained "Self-Organization in Non-Equilibrium Systems".

Consciousness in living organisms is a process which involves the quantum mechanical activities of these TCP and TRP, the ultimate constituents of any matter as well as any mind in the inherent presence of thought force $\left(\mathrm{T}_{\mathrm{F}}\right)$ in vitro and the thought force $\left(\mathrm{T}_{\mathrm{F}}\right)$ in vivo as indicated by Pal et al [1,3]. And these TCP and TRP govern the activities of neurons (not the other way round). Neurons are simply the equipments used to generate consciousness and awareness. The consciousness itself is functioning as an inter-linking agent between the animate and inanimate through the quantum mechanical activities of these TCP and TRP indicated by [3].

\section{Existence of Universal Consciousness}

Pal et al [3] and Pal [7] showed the existence of universal consciousness and explained that the quantized energy $\left(\varepsilon_{T}\right)$ of TCP is responsible to cause the universal consciousness as well as the cosmic microwave background radiation temperature. The individual consciousness owes its origin to the universal consciousness created by the same $\varepsilon_{T}$.

Pal et al [3] have expressed that according to the modern physicists, the universe is the summation of fields, particles, space-time continuum, dark matter, dark energy, void and all the known and unknown parameters of the universe along with all its inhabitants (with or without consciousness), although the universe is always expanding.

The method of integration indicates that

$$
\int d x=x+c
$$

where $\mathrm{c}=\mathrm{a}$ constant. Is there any mathematical fallacy if we like to use 'universe' in the place of ' $x$ ' here? If we at all theoretically like to apply the same method of integration to the whole universe itself, we will have to arrive at 


$$
\left.\int d \text { (universe }\right)=\text { universe }+c
$$

where universe $=$ universe with all its known and unknown parameters as well as its inhabitants (with or without consciousness) and $\mathrm{c}=\mathrm{a}$ constant. The constituents of the universe are fields, particles, space-time continuum, dark matter, dark energy, void, all its inhabitants (with or without consciousness) and all the other unknown parameters of the universe that we have not yet faced. We simply propose to apply the method of integration theoretically over the universe as a whole with all its known and unknown parameters and all the inhabitants (with or without consciousness). If we at all theoretically like to do so, we will mathematically arrive at a constant.

What is this constant here? It is our opinion that this constant is the universal consciousness that exists throughout the universe in the form of universe wide web (uww) covering fields, particles, space-time continuum, dark matter, dark energy, void and all its known and unknown parameters along with all its inhabitants (with or without consciousness). This universal consciousness is to be taken into account, but usually ignored.

Many physicists agree with the idea that consciousness is nonlocal, fundamental in the universe and consciousness is very much a part of the universe, like other objects. It is to be noted that $\boldsymbol{\varepsilon}_{T}$, the quantized energy of TCP represents universal consciousness.

Nelson [9], Director of Global Consciousness Project, has observed through the experimentation that coherent consciousness creates order in the world; and subtle interactions link us with each other and the Earth. When human consciousness becomes coherent and synchronized, the behavior of random systems may change. Quantum event based random number generators (RNGs) produce completely unpredictable sequences of zeroes and ones. But when a great event synchronizes the feelings of millions of people, our network of RNGs becomes subtly structured. The probability is less than one in a billion that the effect is due to chance. The evidence suggests an emerging noosphere, or the unifying field of consciousness described by sages in all cultures. This evidence signifies and proves the existence of universal consciousness.

The existence of universal consciousness is explained by Radin [10] through experimentation as it is expressed in his book The Conscious Universe: The Scientific Truth of Psychic Phenomena. Further, Consciousness, not matter, is the ground of all existence, declares University of Oregon physicist Goswami through his published (1993) book, "The Self-Aware Universe: How Consciousness Creates the Material World".

As per Penrose [11], consciousness is a part of the universe. Van De Bogart [12] explained, "Since consciousness is a part of the universe it then follows that all consciousness, and the universe, are of the same matrix of energy fields".

\section{What is the Exact Definition of Mind? What is Mind?}

We observe a great controversy concerning the exact definition of mind. There are two apparently opposite views: one is the substantial view and the other is the functional view.

In the substantial view, the mind is a type of substance. Mind is a finer matter having an autonomous existence. Mind is a single entity, perhaps having its base in the brain but distinct from it. In its most extreme form as in the Indian Upanishads and Vedanta, the mind is not only a finer matter but also it is an entity wholly separate from the body, in fact a manifestation of the soul, which will survive the body's death in the form of the spiritual body or mental body [called Linga Sharira or Sukshma Sharira in Sanskrit] as expressed by Vivekananda [13] who indicated that this mental body bears all the mental impressions. This mental body is also called 'spirit'.

In the functional view, the mind is closely related to the functions of the brain and can have no autonomous existence beyond the brain, nor can they survive its death. In this view, mind is a 'state' created by the activities of the brain with other parts of the nervous system as it is indicated by cognitive neuro-scientists and Artificial Intelligence (AI) scientists. According to them 'minds are simply what brains do'. In this functional view, mind is a subjective manifestation of consciousness: the human brain's ability to be aware of its own existence. The concept of the mind is therefore a means by which the conscious brain understands its own operations.

The modern cognitive neuroscientists generally accept the fact that the "mind" is not an isolated entity and the mind is a state created by the activities of brain with other parts of the nervous system (CNS, PNS along with ANS). Although the mind is generally accepted to be an abstract having no spatial location or public observability, yet it is a type of fine matter according to the ancient Indian Upanishads and Vedanta. The Vedanta indicates that the universe exists along with the universal consciousness. Pal et al $[1,3]$ explained that this universal consciousness is a functional state of the Universal Mind (UM). This UM is constituted by these TCP and TRP which, in turn, are the ultimate constituents of any matter and any mind in the inherent presence of thought force $\left(\mathrm{T}_{\mathrm{F}}\right)$ in vitro and thought force $\left(\mathrm{T}_{\mathrm{F}}\right)$ in vivo. It is to be noted that these TCP and TRP are the ultimate constituents of any matter in the inherent presence of thought force $\left(\mathrm{T}_{\mathrm{F}}\right)$ in vitro. And these TCP and TRP are the ultimate constituents of any mind in the inherent presence of thought force $\left(\mathrm{T}_{\mathrm{F}}\right)$ in vivo. Pal et al $[1,3]$ explained that any matter as well as any individual mind is constituted by these TCP and TRP in the inherent presence of Thought force $\left(\mathrm{T}_{\mathrm{F}}\right)$ in vitro and Thought force $\left(\mathrm{T}_{\mathrm{F}}\right)$ in vivo.

Modern Scientists are not yet able to understand how the brain works to make the mind. They know that brain has got neurons that communicate across synapses by releasing a neurotransmitter, and that generates electrical impulses, 
and the receiving neuron then talks to its neighbor neurons the same way. If the mind depends on the brain, then all aspects of the mind are going to depend on these simple electrical, chemical processes. According to this concept, the existence of the UM requires the existence of the universal brain to form the UM. The concept of universal brain is not logically acceptable. Thus the concept that the mind depends on the brain becomes questionable if the existence of the UM is valid.

5.1. It appears that scientists would have to decide in a purpose to conclude clearly whether mind is a 'state' (created by the activities of the brain with other parts of the nervous system as it is indicated by the functional view of mind) or 'a finer matter' (as it is indicated by the Indian Upanishads and Vedanta).

\section{Special Characteristics of Mind and Consciousness}

[1] The basic mystery of the mind is how does it emerge from pure matter? How do those units that are made of tiny particles, give rise to the unique and essentially private, experience called consciousness? Do the particles that constitute our brain determine what we think and do? Do these tiny particles ultimately govern the thinking ability of the bioelectrical system? Or, are we free to have our own will? Is consciousness just froth sitting on top of the brain's electronics? How consciousness is being operated? Why should a bunch of atoms have thinking ability? Gross answers to all these inquiries are possible if we accept these TCP and TRP as the ultimate constituents of mind and matter in the inherent presence of thought force $\left(\mathrm{T}_{\mathrm{F}}\right)$ in vivo and thought force $\left(\mathrm{T}_{\mathrm{F}}\right)$ in vitro as indicated by $\mathrm{Pal}$ et al [3]. It is to be noted that the thought force $\left(\mathrm{T}_{\mathrm{F}}\right)$ being a primordial quantum field exerts its functions both in vitro and in vivo.

[2] Modern Scientists are not yet able to understand how the brain works to make the mind. They know that brain has got neurons that communicate across synapses by releasing a neurotransmitter, and that generates electrical impulses, and the receiving neuron then talks to its neighbors the same way. If the mind depends on the brain, then all aspects of the mind are going to depend on these simple electrical, chemical processes. According to this concept, the existence of the UM requires the existence of the universal brain to form the UM. The concept of universal brain is not logically acceptable. Thus the concept that the mind depends on the brain becomes questionable if the existence of the UM is valid.

[3] We are what our minds make us. The mind is a very powerful controller of the body. The mind controls everything as indicated by $\mathrm{Pal}$ et al [1,3] and Pal [7]. Mind is conditioned from the time we are young. It gives our abilities, our perceptions, our character and the way we think. From science to religion, from politics to economics, everything is controlled by the human mind. We perceive, we believe and we react. Things that matter are what we think they are. The quest for truth is bafflingly elusive, after all what is the 'truth'? We have come to the realization that if I believe it is true, it indeed is true for me, regardless of how incredible you may think it is. Experiments do not matter, arguments do not matter, reality does not matter, in fact, matter does not matter---it is all in the mind. As a joker succinctly put it, "It is a case of mind over matter-I do not mind and you do not matter".

[4] Consciousness model of Pal et al [1-3] involving TCP, TRP and thought force $\left(\mathrm{T}_{\mathrm{F}}\right)$ signifies the existence of universal consciousness that exists along with the universe. Pal et al [3] showed that this universal consciousness is a functional state of Universal Mind (UM). Pal et al [3] explained that the UM is evolved at the Big Bang from the eternal Void. This Void, in turn, is the source of infinite energy. And this UM is a finer matter. The individual mind being a constituent of the UM is also a finer matter. The constituents of the UM and individual mind are the same. The ultimate constituents of matter and mind are the same as both mind and matter are aspects of one fundamental reality, which is called UM. The brain is the mediating link or interface between the individual mind and body. Pal et al [3] explained that the constituents of the UM are the ultimate constituents of matter itself as everything in this universe is a manifestation of this UM. Pal et al [3] expressed that the UM is constituted by these TCP and TRP in the inherent presence of thought force $\left(\mathrm{T}_{\mathrm{F}}\right)$. Pal et al $[1,3]$ further explained that the ultimate constituents of matter and mind are these TCP and TRP in the inherent presence of thought force $\left(\mathrm{T}_{\mathrm{F}}\right)$ in vitro and thought force $\left(\mathrm{T}_{\mathrm{F}}\right)$ in vivo.

[5] Current scientific views regarding the origin of consciousness vary widely and range from an 'epiphenomenon' arising from neuronal networks, to neuronal quantum processes, to a separate undiscovered scientific entity.

[6] Consciousness is the functional state of mind. Presence of consciousness signifies the presence of mind and vice versa. It is to be understood that consciousness is the realization of existence and consciousness moves up and down on the 'scale of the realization' of existence through the 'sub-conscious', 'conscious' and 'super-conscious' states as indicated by Pal et al [2].

[7] Consciousness may be defined as the 'self-organized' capability of any living being to activate TCP and TRP, the ultimate constituents of mind and matter and to exert its functions. What can generate, maintain and activate TCP and TRP is called animate having 'active consciousness' and what cannot is called inanimate, i.e., devoid of active consciousness.

[8] Continuity of consciousness is found through the 
experimental observations of Parnia[14], Lommel [15], Fenwick [16] and Beauregard \& O'Leary [17 \& 18] and demonstrate the existence of consciousness during the cessation of brain activity and thus support the existence of universal consciousness as well as substantial view of mind as indicated by the Indian Upanishads and Vedanta.

[9] Everything in this universe is interlinked and intertwined through the existence of the quantum mechanical activities of these TCP in the inherent presence of TRP. Pal et al [1,3] showed that the quantized energy $\left(\varepsilon_{T}\right)$ of TCP is responsible to cause the universal consciousness as well as the cosmic microwave background radiation temperature. The individual consciousness owes its origin to the universal consciousness created by the same $\varepsilon_{T}$. Ultimately this $\varepsilon_{T}$ represents universal consciousness. This universal consciousness functions as a universe wide web (uww) covering the universe as a whole with all its parameters (including void) and inhabitants (with or without consciousness). In this picture, uww of consciousness, quantum concepts like wave particle dualism, position momentum uncertainty, nonlocality and concept of unified field become somewhat understandable as all the entities of this universe are interlinked and intertwined. In this picture, the universal consciousness replaces ether of yesteryears and contains the whole of the universe in its fold. The 'spooky action-at-a-distance' may thus be built in nature through the existence of these TCP and TRP in the presence of thought force $\left(\mathrm{T}_{\mathrm{F}}\right)$.

[10] In a purpose to conclude clearly, it appears, that scientists would have to decide whether mind is a 'state' (created by the activities of the brain with other parts of the nervous system as it is indicated by the functional view of mind) or 'a finer matter' (as it is indicated by the Indian Upanishads and Vedanta).

[11] The science of the mind may be connected with the science of the body. It is possible that the modern mind has been developed to get its present shape by the directive of the UM. The mind is an all-purpose computer responding impartially to the world around it; and this mind had, through natural selection, evolved to respond in a particular way to particular environmental circumstances. Humans are 'adaptation executors' carrying out programs written into the mind's machinery long ago. "The machinery does not know its own programming", said Cosmides and Tooby [19-21], intellectual leading evolutionary psychologists. The evolutionary psychologists see the mind as pre-programmed, made up of specialized mechanisms---'modules' or 'organs'. The evolutionary psychologists argue that their job is to approach the mind as an ancient engineering project, developing and testing out hypotheses about what 'designed problems' needed solving. Evolutionary psychologists thus signify the existence of the UM. Such an approach offers a badly needed bridge between psychology and the natural sciences. A plausible bridge between psychology and the natural sciences can be achieved through the developed consciousness model.

\section{Characteristics of Soul ( $\cong$ VOID), Consciousness, Mind and Brain}

Consciousness model of Pal et al [1-3] involving TCP, TRP and thought force $\left(\mathrm{T}_{\mathrm{F}}\right)$ signifies the existence of universal consciousness that exists along with the universe. Pal et al [3] showed that this universal consciousness is a functional state of the Universal Mind (UM). Pal et al [3] explained that the UM is evolved at the Big Bang from the eternal Void. The UM is constituted by these TCP and TRP in the inherent presence of thought force $\left(\mathrm{T}_{\mathrm{F}}\right)$. This thought force $\left(\mathrm{T}_{\mathrm{F}}\right)$ is an expression of universal consciousness.

These TCP and TRP, the constituents of the UM and the ultimate constituents of matter and mind are conceived here to be originated from the eternal Void at the Big Bang to evolve the space-time continuum and the UM along with the universal consciousness.

Pal et al [3] explained that the eternal Void has been covered by the mind to function as the Soul of the individual being. In the universe, behind the UM, there is a Soul ( $\cong$ VOID). In the individual, behind the individual mind (which is a constituent of the UM), there is also a Soul ( $\cong$ VOID).

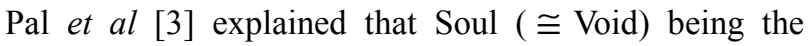
master ruler of the body exerts its functions through the finer instrument called mind. The mind (with the help of TCP and TRP) exerts its functions through the brain and spinal cord (CNS) along with the other parts of the nervous system (PNS along with ANS) in the biological systems in order to grasp this physical universe, of course, in the inherent presence of consciousness. This consciousness itself is acting as an inter-linking agent between the animate and inanimate through the quantum mechanical activities of these TCP and TRP. Consciousness is defined here as the 'self-organized' capability of any living being to activate TCP and TRP, the ultimate constituents of mind and matter. This consciousness, in turn, is the quantized energy $\left(\varepsilon_{T}\right)$ of TCP.

Any matter as well as any individual mind is constituted by these TCP and TRP that, in turn, are originated from the same eternal Void. Thus the individual mind is operated by these TCP and TRP that, in turn, are ultimately governed by the same eternal Void. The individual mind being a constituent of the UM has covered the eternal Void to serve the role of individual Soul. This eternal Void is thus the common source and the source is still with us indicated by Bhaumik [4]. This Void serves the role of Soul being covered by the mind.

In order to develop a possible relationship among matter, mind and consciousness, Pal et al [1,3] expressed the 
existence of TCP, TRP and thought force $\left(T_{F}\right)$. This $T_{F}$ is the primordial quantum field that, in turn, exerts its functions both in vitro and in vivo.

\section{TCP and TRP Play Prominent Roles to Form a Possible Gross Bridge between Mind and Matter}

Pal et al [3] showed that these TCP and TRP are the ultimate constituents of any matter as well as any mind in the presence of thought force $\left(\mathrm{T}_{\mathrm{F}}\right)$ in vitro and thought force $\left(\mathrm{T}_{\mathrm{F}}\right)$ in vivo. It is to be noted that these TCP and TRP are the ultimate constituents of any matter in the inherent presence of thought force $\left(\mathrm{T}_{\mathrm{F}}\right)$ in vitro. And these TCP and TRP are the ultimate constituents of any mind in the inherent presence of thought force $\left(\mathrm{T}_{\mathrm{F}}\right)$ in vivo.

Pal [22] explained mental processes involving consciousness through the consciousness model incorporating quantum mechanical activities of TCP and TRP in the presence of Thought force $\left(\mathrm{T}_{\mathrm{F}}\right)$ in vitro and Thought force $\left(\mathrm{T}_{\mathrm{F}}\right)$ in vivo.

Georgiev [23] explained through experimental observation that our mind operates at $100 \mathrm{GHz}$ (dynamical timescale of 10 picoseconds). It is found that the calculated frequency of TCP is $75 \mathrm{GHz}$ that is close to $100 \mathrm{GHz}$. And the calculated time period of the TCP $=1.33 \times 10^{-11} \mathrm{sec}$ that is equivalent to 10 picoseconds $=10^{-11} \mathrm{sec}$.

It appears that there is a significant relationship between the operational mind and the quantum mechanical activities of these TCP and TRP. In this way, the mind is a state created by these TCP and TRP. Or the mind is constituted and operated by these TCP and TRP. These TCP and TRP can thus form a possible bridge between the mind and matter in the presence of thought force $\left(\mathrm{T}_{\mathrm{F}}\right)$ in vitro and thought force $\left(\mathrm{T}_{\mathrm{F}}\right)$ in vivo.

\section{The Physical World is nothing but a Projection of the Mind Consisting of the TCP and TRP that, in Turn, are the Ultimate Constituents of any Matter also}

Pal et al $[1,3]$ explained that the universe exists along with the universal consciousness. This universal consciousness is a functional state of the Universal Mind (UM). This UM is constituted by these TCP and TRP which, in turn, are the ultimate constituents of any matter as well as any mind in the inherent presence of thought force $\left(\mathrm{T}_{\mathrm{F}}\right)$ in vitro and thought force $\left(\mathrm{T}_{\mathrm{F}}\right)$ in vivo. It is to be noted that these TCP and TRP are the ultimate constituents of any matter in the inherent presence of thought force $\left(\mathrm{T}_{\mathrm{F}}\right)$ in vitro. And these TCP and TRP are the ultimate constituents of any mind in the inherent presence of thought force $\left(\mathrm{T}_{\mathrm{F}}\right)$ in vivo.

Bhaumik [4] pointed out, "We must conclude, with
Bishop Berkeley, that the physical world is nothing but a projection of the mind. 'I' and the universe somehow participate with one another. Mind affects matter and matter affects mind. Could the answer to the "why" of consciousness lie in John Wheeler's time-bending notion that our "observership brings the universe into being"?

John A. Wheeler clearly indicated that the process of recognizing an observable object is really a type of participation on the part of the observer for a specific object to be observed. This process of recognizing an observable object is possible through the projection of mind of the observer in the presence of his / her consciousness. I will never recognize any external object in the absence of the function of my mind (= consciousness).

This mind (with the help of TCP and TRP), in turn, exerts its functions through the brain with other parts of nervous systems (CNS, PNS along with ANS) in the biological systems in order to grasp this physical universe, of course, in the inherent presence of consciousness. And this mind is the finer instrument through which the Soul

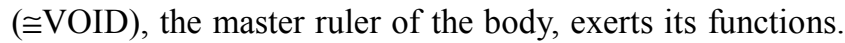
Thus, both the external something and the internal Soul

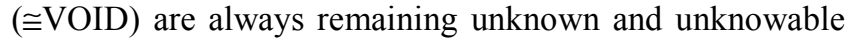
throughout. Their presence can be visualized only in the presence of the function of mind generating consciousness. So, there is always a bridge between the internal world and the external world through the vehicle of the mind (i.e. composed of TCP and TRP) in the presence of consciousness. All forms are only the external expressions of the thoughts projected by the mind. If we can sincerely hold on to a specific thought and project it outside, we can logically create a specific form.

Pal et al $[2,3]$ explained that any matter (as well as mind) being ultimately composed of these TCP and TRP should have some sort of 'mind' as Dyson indicated.

Bhaumik [4] also mentioned, "American psychologist William James stated, "there is only one primal 'stuff' of which everything is composed. David Bohm and Basil Hiley said that at some level of reality (in the pre-space / implicate order), mind and matter merge. Bhom maintained that implicit in the quantum potential was a "mind-like quality in matter," which he identified with the notion of active information. Even an electron, he argues, has a rudimentary "mental" aspect. If this is true, it's reasonable to ask whether our brains, as material outgrowths of this process, have evolved to operate in perfect resonance with this active information. "One could say," Bohm and Hiley allow, "that through the human being, the universe is making a mirror to observe itself."

Freeman J. Dyson expressed: "It appears that mind, as manifested by the capacity to make choices, is to some extent inherent in every atom. The second level is our direct human experience of our own consciousness. The third level is the entire universe. The universe as a whole is also weird, with laws of nature that make it hospitable to the growth of mind". Thus any matter (as well as 'mind') being ultimately composed of these TCP and TRP should 
have some sort of 'mind' as Dyson and Bhom indicated.

\section{TCP and TRP Play Significant Roles in the field of Cognitive Neuro- Science}

Pal et al [2] and Pal [24] showed that these TCP and TRP in the presence of thought force $\left(\mathrm{T}_{\mathrm{F}}\right)$ in vitro and thought force $\left(\mathrm{T}_{\mathrm{F}}\right)$ in vivo play significant roles in the field of cognitive neuro-science.

The mind of animate must create the wave towards any sensation in order to perceive it. In every phenomenon in nature we contribute at least half share and the nature brings half as indicated by Vivekananda [25]. If our half share is taken off, the thing must stop to exist for us. Nobody knows what is external; when we try to know it, it has to become that material which we furnish by projecting the mind (consisting of TCP and TRP) in the presence of consciousness. The reflections formed in the physical eye (through stimuli) only serve to call the attention of the conscious mind to the objects of its perception. Perception is a faculty by which mind learns to know what is going on within itself. To see a thing is to perceive the existence of its appearance within one's own mind. To see a thing is identical with touching it with the mind. The individual mind of a man being one with the Universal mind extends through space; and the things themselves that exist within the periphery of our mind can be perceived through the consciousness, the apparent center of which is generally thought to be located in the brain. If the mind touches an object through the quantum mechanical activities of these TCP and TRP, the impressions have to travel all the way to the brain. What we know of the external is as it is moulded, formed, fashioned by our own mind, which, in turn, exerts its actions through the brain.

The reigning tenet of quantum mechanics is the uncertainty principle. A consequence of the uncertainty principle is that the presence of an observer or experimenter determines the outcome of the observation or experiment. Simply stated, this means there is no objective reality; you 'create' what you see through the quantum mechanical activities of these TCP and TRP in the presence of consciousness. The quantized energy $\left(\varepsilon_{T}\right)$ of TCP represents universal consciousness. The individual consciousness owes its origin to the universal consciousness created by the same $\varepsilon_{T}$. Pal et al $[1,3]$ explained that these TCP and TRP are the ultimate constituents of any matter as well as any mind in the inherent presence of thought force $\left(\mathrm{T}_{\mathrm{F}}\right)$ in vitro and the thought force $\left(\mathrm{T}_{\mathrm{F}}\right)$ in vivo.

It is to be noted that TCP cannot exist without TRP and vice versa. These TCP and TRP function like wavicle: wave-particle duality. Both the TCP and TRP are interchangeable in the presence of consciousness, of course, in the inherent presence of the Soul ( $\cong$ Void which is the source of infinite energy) to complete the process of observation in order to see the observable 'object'.
There is 'something' which is outside, which is only the occasion, the suggestion; and upon that 'suggestion' I project the TCP of my mind with the help of consciousness to see (identify) this external 'suggestive something'.

What is the process of observation? How do we see? It is to be noted that these TCP and TRP are interchangeable in the presence of consciousness to complete the process of observation in order to see the observable 'object'. When I project the TCP of my mind with the help of consciousness to see the external observable 'object', this TCP from my mind is converted into TRP in the presence of my consciousness. This TRP cannot exist without TCP. These TRP and TCP thus 'create' the observable object that I see.

TCP from this observable 'object' is to be returned to me in order to complete the process of observation for seeing the observable 'object'. This returned TCP from the object is to be converted into TRP in the presence of my consciousness and this converted TRP is to be retained and stored within my mind for future use. This conversion of TCP from the observable 'object' into TRP within my mind is necessary for forming an impression of the object within my mind so that I can retain that image with the help of TRP within my mind for future 'recognition' when I would come across the same 'thing'. This is possible through the power of the Soul ( $\cong$ Void which is the source of infinite energy) in the presence of consciousness.

It is to be noted that these TCP and TRP are the ultimate constituents of any matter as well as any mind in the inherent presence of thought force $\left(\mathrm{T}_{\mathrm{F}}\right)$ in vitro and the thought force $\left(\mathrm{T}_{\mathrm{F}}\right)$ in vivo. It is to be understood that when we try to see an observable external 'object', it has to become that material which we furnish by projecting the mind (consisting of TCP and TRP) in the presence of consciousness and it takes the form that I see.

Thus, there is no objective reality; I 'create' what I see through the quantum mechanical activities of these TCP and TRP in the presence of my consciousness. These TCP and TRP are interchangeable in the presence of consciousness to 'create' and then see the observable 'object'. "Matter is an expression of mind, not separate from mind, but mind manifested materially".

Consciousness, not matter, is the ground of all existence, declares University of Oregon physicist Goswami through his published (1993) book, "The Self-Aware Universe: How Consciousness Creates the Material World". He accepts the Vedantic view and holds that the universe is self-aware, and that consciousness creates the physical world. Matter is an expression of mind, not separate from mind, but mind manifested materially.

John Wheeler strongly believed that "in defining any useful concept of reality" we have to take into account "the indispensable place of the participating observer--evidenced in quantum mechanics" as indicated by Bhaumik [4]. Wheeler has speculated that reality is created by observers in the universe. His time-bending notion is that our "observership brings the universe into being".

Wheeler indicated that the process of recognizing an 
observable object is really a type of participation on the part of the observer for a specific object to be observed. This process of recognizing an observable object is possible through the projection of mind of the observer in the presence of his / her consciousness.

How could an object's existence depend upon the act of observation? This is due to the fact that an object's existence as well as the act of observation through the prevailing consciousness is totally dependent on the existence of the quantum mechanical activities of these TCP and TRP in the presence of consciousness. The quantized energy $\left(\varepsilon_{T}\right)$ of TCP represents universal consciousness. The individual consciousness owes its origin to the universal consciousness created by the same $\varepsilon_{T}$. Pal et al $[1,3]$ explained that these TCP and TRP are the ultimate constituents of any matter as well as any mind in the inherent presence of thought force $\left(\mathrm{T}_{\mathrm{F}}\right)$ in vitro and the thought force $\left(\mathrm{T}_{\mathrm{F}}\right)$ in vivo.

How do we all see the same things? Because we all have similar parts (i.e. TCP and TRP) of the Universal Mind that, in turn, is constituted by these TCP and TRP. Those who have like minds will see like things, and those who have not, will not see alike. I will never know that external 'something' in the absence of the function of my mind

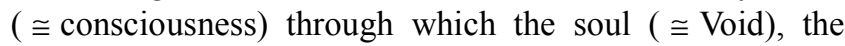
master ruler of the living body, exerts its functions. Thus both the external something and the internal Soul are

always remaining unknown and unknowable throughout. Their presence can be visualized only in the presence of the function of mind generating consciousness. So, there is always a bridge between the internal world and the external world through the vehicle of mind (composed these TCP and TRP) in the presence of consciousness.

In our view, the brain is only a fine "instrument" through which the mind exerts its functions with the help of TCP and TRP. The "binding problem" associated with the concepts of coherence can also be tackled through the quantum mechanical activities of these TCP and TRP. A single unified experience of an object having different features is, in our view, caused by the Soul ( $\cong$ VOID), the master ruler of the body. And this Soul, with the help of consciousness, exerts its functions through the finer instrument called "mind". Being guided by the Soul, the mind can, with the help of TCP and TRP, correlate and assemble all the different stimuli (relating to the different features of an object) into a unified experience of a single thing through the utilization of the instrumental brain. The "science of observation" in the field of "cognitive neuroscience" can be explained through the existence and function of Soul and mind in the inherent presence of consciousness.

\section{Mode of Perception}

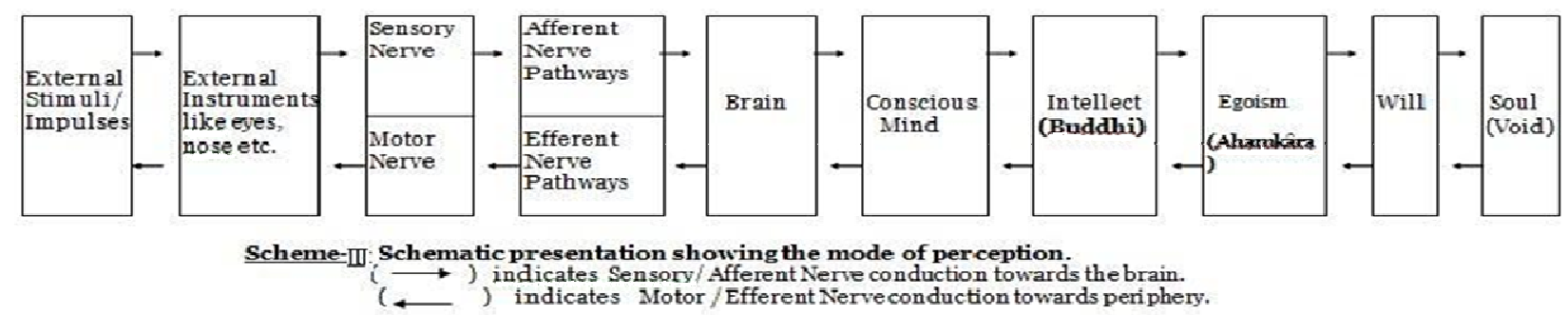

Regarding the perception, let us see Scheme-III for the explanation expressed by Sânkhya psychology as indicated by Vivekananda [26] In the case of vision, for instance, there are, first of all, the instruments of vision, the eyes. Behind the instruments (eyes), there is the organ of vision or 'Indria' (Sense organ), the optic nerve and its centers which are not the external instruments but without which the eyes will not see. The external sensations cannot be carried to the brain by the eyes alone if the sensory nerves (here optic nerve) and its centers are destroyed. Still more is needed for the perception. The mind (or Manas in Sanskrit) must come and attach itself to the organ to play its own role. Let us suppose that we are absorbed in reading a detective novel with close attention and if a bell rings at that time, we will not perhaps, hear the bell ring. The pulsation of that sound came to our ears, struck the tympanum; the impression was carried by the nerve into the brain. If the whole process was completed up ---catching, carrying and conducting the impulse to the brain, then why did we not hear? Something else was missing in the connection---the mind was not attached to the organ. When the mind detaches itself from the organ, the organ may bring any news to it, but the mind will not receive it. When mind attaches itself to the organ, then alone it is possible for the mind to receive the news. Yet, even that does not complete the whole circuit. The instrument may bring the sensation from the outside, the organ may carry it inside, the mind may attach itself to the organ, and yet the perception may not be complete. One more factor is necessary. There must be a reaction within. With this 
reaction comes knowledge. The sensation must be carried to the intellect (or BUDDHI), the determinative, reactive state of mind. The mind, after receiving the current of news from the brain, presents it to the intellect, which groups it in relation to the pre-received impressions and sends a current of reaction and perception becomes possible with that reaction. When the reaction comes from the intellect, along with it flashes the external world and egoism. Here then is the will. But everything is not complete. One more step is required. All the ideas in the mind must be gathered and projected on something that is stationary relatively to the body and mind. This internal 'something' stationary upon which our sensations, carried by the mind and intellect, are placed and grouped and formed into a unity, is what is called the Soul ( $\cong$ VOID), the master ruler of the body (see Scheme-III). The impulse is presented to the

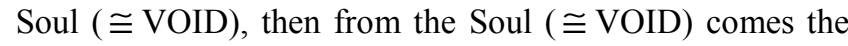
order which goes down in the same sequence to the intellect, to the mind, to the brain, and the brain conveys it to the instruments through efferent nerve pathways and then the perception is truly complete (see Scheme-III).

According to the Sânkhya psychology as indicated by Vivekananda [26], the reactive state of mind called intellect (or BUDDHI) is the out-come or a certain manifestation of the cosmic mind (MAHAT) called the Universal Mind (UM).

\section{Discussion and Conclusion}

\subsection{Discussion}

Pal et al [1,3] explained research works of several eminent scientists like Hameroff and Penrose, Wackermann, Thaheld and Wolf.

All these experiments ultimately signify and justify the conspicuous existence of TCP and TRP, the ultimate constituents of matter and mind in the inherent presence of thought force $\left(\mathrm{T}_{\mathrm{F}}\right)$ in vitro and the thought force $\left(\mathrm{T}_{\mathrm{F}}\right)$ in vivo.

The existence of functional paranormal power like the Extra Sensory Perception (ESP) and Psychokinesis (PK) significantly indicates the existence of these TCP and TRP in the inherent presence of thought force $\left(\mathrm{T}_{\mathrm{F}}\right)$ in vitro and the thought force $\left(\mathrm{T}_{\mathrm{F}}\right)$ in vivo. These TCP, TRP and the thought force $\left(\mathrm{T}_{\mathrm{F}}\right)$ in vitro and thought force $\left(\mathrm{T}_{\mathrm{F}}\right)$ in vivo can exert their roles mentally (internally) as well as physically (externally).

Bhaumik [4] pointed out, "Sheldrake has advanced the notion of an "extended mind" that can "reach out" to influence things well beyond the brain's boundaries. Like Nobel physicist Brian Josephson, he is deeply interested in finding a scientific explanation of psi phenomenon such as telepathy. A convincing proof of such phenomenon will obviously demonstrate that consciousness is not merely confined within the skull; it is capable of biological nonlocality. Mind is entangled with matter as matter is entangled with mind."
The existence of TCP, TRP and thought force $\left(\mathrm{T}_{\mathrm{F}}\right)$ in vitro and thought force $\left(\mathrm{T}_{\mathrm{F}}\right)$ in vivo may provide plausible guidelines to lucidly explain the evolution of the universe with fundamental laws of natural science like physics, chemistry and biology (with consciousness).

\subsection{Conclusion}

We showed here a possible bridge between the mind and matter. We also explained that the physical world is nothing but a projection of the mind consisting of TCP and TRP that, in turn, are the ultimate constituents of any matter also

It appears that the standard model of physics is to be correctly tuned by ascertaining the constituents of quarks and leptons in the presence of unified field in order to form a possible gross bridge between mind and matter, present physics and cognitive science, psychology and natural sciences, classical physics and quantum physics.

\section{References}

[1] D. Pal and A.U. De, Physics of consciousness and its model may provide guidelines to solve Many scientific problems. Neuroquantology 1: 17-28(2004)

[2] D. Pal and A.U. De, Consciousness model: Significance of thought-carrying particles and thought-retaining particles in quantum measurement as well as cognitive problem. Neuroquantology 2: 115-116 (2005)

[3] D. Pal and A.U. De, The cosmic microwave background radiation temperature signifying the existence of the thought-carrying particle, thought retaining particle and thought force. NeuroQuantology 10: Issue3; 428-442 (September 2012)

[4] M. Bhaumik, Code Name GOD. (Penguin Books India Pvt. Ltd., 11 Community Centre, Panchsheel Park, New Delhi 110017 , India) pp. 132-133; 161-162; 167; 171; 177; 183 and 184. 185-186; 89-190; 198 (2006)

[5] D. Pal, Existence of thought force and its characteristics. American Journal of Modern Physics Vol. 2, No. 6, 2013, pp. 364-374. doi: 10.11648/j.ajmp.20130206.23

[6] V. F. Weisskopf, The Origin of the Universe, The World of Physics, (Simon and Schuster, 1230 Avenue of Americas, New York 10020) 3, pp. 10 and 314 (1987)

[7] D. Pal, Existence of universal consciousness and its characteristics. Accepted for publication in 2014 International Conference on Advanced Education and Management (ICAEM2014) Beijing, China (2013)

[8] I. Prigogine and G. Nicolis, Self-Organization in NonEquilibrium Systems. (Wiley 1977) ISBN 0471024015.

[9] R. Nelson, Director, Global Consciousness Project, Princeton, New Jersey. (2009) rdnelson@princeton.edu

[10] D. Radin, The Conscious Universe: The Scientific Truth of Psychic Phenomena. (Harper Edge) (1997) ISBN 0-06251502-0.

[11] R. Penrose, Shadows of the Mind: A Search for the Missing Science of Consciousness. (Oxford University Press) (1994) 
[12] W. Van De Bogart, Earth portals: Exploring New Metaphors of Consciousness 1993 willard@earthportals.com

[13] S. Vivekananda, The Cosmos (the Microcosm). The complete works of Swami Vivekananda. (Advaita Ashrama, India) 2: pp-212 (1989)

[14] S. Parnia, Do reports of consciousness during cardiac arrest hold the key to discovering the nature of consciousness? Medical Hypotheses 69(4): 933-937 (2007)

[15] P van. Lommel, R. Wees, V. Meyers and I. Elfferich, NearDeath Experience in Survivors of Cardiac Arrest: A prospective Study in the Netherlands. The Lancet (9298): 2039-45 (2001)

[16] P. Fenwick, S. Parnia, D.G. Waller, and R. Yeates, A qualitative and quantitative study of the incidence, features and aetiology of near-death experiences in cardiac arrest survivors. Resuscitation 48: 149-156 (2001)

[17] M. Beauregard and D. O'Leary, The spiritual brain: A neuroscientist's case for the existence of the soul. (Harper Collins Publishers) (2008)

[18] M. Beauregard and V. Paquette, Neural correlates of a mystical experience in Carmelite nuns. Neuroscience Letters 405, 186-190 (2006)

[19] L. Cosmides and J. Tooby J. From evolution to behavior: Evolutionary psychology as the missing link. (In J. Dupre (Ed.), The latest on the best: Essays on evolution and optimality, Cambridge, MA, The MIT Press. (1987)

[20] L. Cosmides, J. Tooby, J. Barkow, The adapted mind:
Evolutionary psychology and the generation of culture. (New York: Oxford University Press. 1992)

[21] L. Cosmides and J. Tooby, Beyond intuition and instinct blindness: Towards an evolutionary rigorous cognitive science. Cognition; 50 (1-3): 41-77 (1994)

[22] Dhananjay Pal, Explanation of Mental Processes Involving Consciousness through the Consciousness Model Incorporating Quantum Mechanical Activities of ThoughCarrying Particle (TCP) and Thought Retaining Particle (TRP) in the Presence of Thought Force (TF) in vitro and Thought Force (TF) in vivo, American Journal of Modern Physics. Vol. 2, No. 6, 2013, pp. 396-403. doi: 10.11648/j.ajmp.20130206.28

[23] D. D. Georgiev, Consciousness operates beyond the timescale for discerning time intervals: implications for Qmind theories and analysis of quantum decoherence in brain. NeuroQuantology 2: 136 and 140-141 (2004)

[24] Dhananjay Pal, Interpretation of Quantum Measurement as Well as Cognitive Problem Through the Consciousness Model, American Journal of Modern Physics. Vol. 2, No. 6, 2013, pp. 375-381. doi: 10.11648/j.ajmp.20130206.24

[25] Vivekananda "Meditation", "The complete works of Swami Vivekananda, Advaita Ashrama, 5, Dehi Entally Road Cal7000014, 1stedn.; 1989; Vol-4:229; "Vedanta", ibid; Vol3:403-404; COSMOLOGY, ibid.; Vol-2:441.

[26] Swami Vivekananda, The Vedanta Philosophy. The real and the apparent Man. The complete works of Swami Vivekananda. (Advaita Ashrama 1989) 1: P-359-360; The Real and the Apparent Man, ibid.; 2: P-263. 